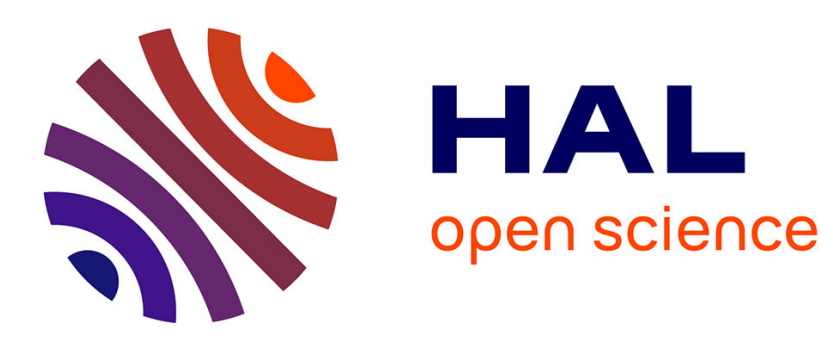

\title{
Macroscopic Modelling of Gas Flow through a Fractured Porous Medium
}

Pascale Royer, Jean-Louis Auriault

\section{To cite this version:}

Pascale Royer, Jean-Louis Auriault. Macroscopic Modelling of Gas Flow through a Fractured Porous Medium. International Symposium on Dynamics of Fluids in Fractured Rocks, Feb 1999, Berkeley, CA, United States. pp.354-358. hal-01717325

\section{HAL Id: hal-01717325 \\ https://hal.science/hal-01717325}

Submitted on 26 Feb 2018

HAL is a multi-disciplinary open access archive for the deposit and dissemination of scientific research documents, whether they are published or not. The documents may come from teaching and research institutions in France or abroad, or from public or private research centers.
L'archive ouverte pluridisciplinaire HAL, est destinée au dépôt et à la diffusion de documents scientifiques de niveau recherche, publiés ou non, émanant des établissements d'enseignement et de recherche français ou étrangers, des laboratoires publics ou privés. 


\title{
Macroscopic Modelling of Gas Flow through a Fractured Porous Medium
}

\author{
P. Royer, J.L. Auriault, Laboratoire “ Sols, Solides, Structures ", UJF, INPG, CNRS, Grenoble, \\ France (Pascale.Royer@hmg.inpg.fr, Jean-Louis.Auriault@hmg.inpg.fr).
}

Summary: This work is concerned with modelling the seepage of gas through a rigid fractured medium. It summarises results obtained using the homogenization method for periodic structures. Thereby, unlike the phenomenological approaches, the macroscopic behaviour is deduced from the physics at the microscopic scales, without any prerequisite. Then, the result of the comparison of the homogenized model with the model of Warren and Root for a slightly compressible fluid flow is presented. Finally, a correction of pseudo steady state phenomenological models is proposed.

\section{Introduction}

A fractured porous medium is a dual porosity medium, i.e., it consists of two interacting porous systems whose permeabilities are very different. One of the two porous structures is associated with the fractures and the other one with the porous matrix. The internal disorder repetition may allow a large-scale continuous description. Two kinds of approaches may be distinguished: i) Directly macroscopic approaches ; ii) Upscaling methods.

The first investigations were on the basis of phenomenological approaches, i.e., directly macroscopic approaches (Barenblatt et al. 1960, Barenblatt 1963, Warren \& Root 1963). The first model (Barenblatt et al. 1960) shows an important characteristic of dual porosity systems: the interporosity flow, i.e. the fluid exchange between both constitutive media. In these phenomenological models, a pseudo steady state flow is described. They are based on the conjecture that the interporosity flow occurs in response to the fracture-porous matrix difference in pressure.

On the other hand, homogenization techniques allow the determination of an equivalent macroscopic behaviour by upscaling the local description. By definition, this macroscopically equivalent medium behaves " in average" like the initial heterogeneous medium under a given excitation. The condition required for applying these methods is the separation of scales. Homogenization techniques have already proved to be efficient for modelling fluid flow in porous media. In particular, the homogenization method for periodic structures leads to precise descriptions since no macroscopic prerequisite is required. When looking for a macroscopic equivalent description of fluid flow in fractured porous media, three separated scales whose characteristic lengths are very different may be under consideration : the pore scale, the fracture scale and the macroscopic scale. An innovative three scale homogenization method for periodic structures was established in Auriault and Boutin (1992), Auriault and Boutin (1992), Royer and Auriault (1994), and Royer (1994). Pore-flow and fracture-flow are controlled by Stokes equations. This upscaling method allows the influence of the local effects, i.e. at the pore scale, to be conveyed to the macroscopic level.

The goals of this paper are two-fold: i) to present the model of gas flow in fractured porous media derived via homogenization; ii) to present the result of the comparison of the 
homogenized model with the phenomenological models. Since there is no dual porosity phenomenological model for highly compressible fluid flow, this comparison is carried out for a slightly compressible fluid.

In section 2, the description obtained by the three scale homogenization approach is presented. Attention will be focused on the result itself. Section 3 relates specifically to comparing the homogenized model with the model of Warren and Root for a slightly compressible fluid. Finally, a correction of the interporosity flow term is proposed, which yields a more accurate description for transient regimes.

\section{Homogenization Model of Gas Flow Through A Fractured Porous Medium}

\subsection{General}

To fit the homogenization method for periodic structures to three scales problems, the medium is assumed to be doubly periodic. There is no loss of generality by introducing the assumption of periodicity (Auriault, 1991). No specific internal geometry is at issue for both periods, the work is aimed towards deriving a general macroscopic model. At the pore scale, consider the medium to be $\Omega$-periodic and its characteristic length to be $l$. The solid and the pores occupy the domains $\Omega_{s}$ and $\Omega_{p}$, respectively, and their common boundary is $\Gamma$ (Fig. 1a). A second periodic structure exists at the fracture level, whose period is $\Omega^{\prime}$ and whose characteristic length is $l^{\prime}$, such that $l^{\prime} \gg l$. The porous matrix and the fractures occupy the domains $\Omega_{s p}^{\prime}$ and $\Omega_{f}^{\prime}$, respectively, and their common boundary is $\Gamma^{\prime}$ (Fig. 1b). In a given medium, $l$ and $l^{\prime}$ are defined but the macroscopic characteristic length, $l^{\prime \prime}$, must be chosen such that $l^{\prime \prime}>>l^{\prime}$. Therefore, the dual porosity medium exhibits two separations of scales instead of one in the single porosity case: $l^{\prime} / l^{\prime \prime}<1$ between the fracture scale and the macroscopic level, $l / l^{\prime}<<1$ between the pore scale and the fracture scale.

If the first condition is not checked the homogenization cannot be applied because the macroscopic scale and the fracture scale are not separated. If the second one is not checked, it means that the medium is a two scale medium. Thus, it is assumed that both conditions of separation of scales are satisfied, so that the medium is a three scale medium and the homogenization theory can be applied.

The macroscopic behaviour of such a medium under fluid flow depends upon the relative order of magnitude between both scale ratios. The largest coupling effects between the pore-flow and the fracture-flow appear when the scales are equally separated (Auriault \& Boutin 1992, Auriault \& Boutin 1992, Royer \& Auriault 1994, and Royer 1994), i.e., when $\frac{l}{l^{\prime}}=O\left(\frac{l^{\prime}}{l^{\prime \prime}}\right)=O(\varepsilon)$. This is the case under consideration hereafter for the investigation of gas flow in a rigid fractured medium. 


\subsection{Local description}

In the pores $\left(\Omega_{p}\right)$ and in the fractures $\left(\Omega_{f}^{\prime}\right)$, gas flow is governed by Navier-Stokes equations. For slow flows, inertial and transient terms of Navier-Stokes equations can be neglected (Auriault et al. 1990). For the sake of simplicity, assume the fluid to be linear. Thus, the gas state equation is a linear relationship between the fluid pressure and the fluid density. Let us assume the system to be initially at rest: fluid velocity is zero-valued and pressure and density are constant ( $P_{0}$ and $\rho_{0}$, respectively). Thus, the problem is governed by the following set of equations with $k=p$ in the pores $\left(\Omega_{p}\right)$ and $k=f$ in the fractures $\left(\Omega^{\prime}{ }_{f}\right)$.

$\mu \Delta \vec{v}_{k}+(\lambda+\mu) \vec{\nabla}\left(\vec{\nabla} \cdot \vec{v}_{k}\right)-\vec{\nabla} P_{k}=\overrightarrow{0}$

$\frac{\partial \rho_{k}}{\partial t}+\vec{\nabla} \cdot\left(\left(\rho_{0}+\rho_{k}\right) \vec{v}_{k}\right)=0$

$\rho_{k}=A P_{k} \quad$ where $A=\frac{\rho_{0}}{P_{0}}$ is a constant

$\vec{v}_{p}=\overrightarrow{0}$ on $\Gamma$

$\vec{v}_{f} \cdot \vec{n}^{\prime}=\left\langle\vec{v}_{p}>_{\Omega} \cdot \vec{n}^{\prime}=\left(\frac{1}{|\Omega|} \int_{\Omega_{p}} \vec{v}_{p} d \Omega\right) \cdot \vec{n}^{\prime} \quad\right.$ on $\Gamma^{\prime}$

$P_{f}=P_{p}$ on $\Gamma^{\prime}$

Fluid pressure and density are $P_{0}+P_{k}$ and $\rho_{0}+\rho_{k}$, respectively, where $P_{k}$ and $\rho_{k}$ are increments.

\subsection{Scaled-up model}

The derived macroscopic behaviour is:

$\phi^{\prime} \frac{\partial P_{f}}{\partial t}+\phi \frac{\partial<P_{p}>_{\text {eff }}}{\partial t}-\vec{\nabla} \cdot\left[\left(P_{0}+P_{f}\right) \tilde{K} f \vec{\nabla} P_{f}\right]=0$

where $\phi^{\prime}=\frac{\left|\Omega_{f}^{\prime}\right|}{\left|\Omega^{\prime}\right|}$ is the fracture porosity and $\phi=\frac{\left|\Omega_{p}\right|}{|\Omega|}$ is the pore porosity.

The term $\phi \frac{\left.\partial<P_{p}\right\rangle_{\phi}}{\partial t}$ shows the fluid exchange between both porous systems. $\left\langle P_{p}\right\rangle_{\phi}$ is defined by $\left\langle P_{p}\right\rangle_{e f f}=\frac{1}{\Omega^{\prime} \mid} \int_{\Omega_{s p}} P_{p} d \Omega$, where $P_{p}$ is defined by the following boundary value problem over $\Omega_{s p}^{\prime}$ :

$\phi \frac{\partial P_{p}}{\partial t}-\vec{\nabla} \cdot\left[\left(P_{0}+P_{p}\right) \tilde{K}_{p} \vec{\nabla} P_{p}\right]=0$

$P_{p}=P_{f} \quad$ on $\Gamma^{\prime}$, 
in which $P_{p}$ is $\Omega^{\prime}$-periodic.

The macroscopic velocity is $\vec{V}=-\widetilde{K}_{f} \vec{\nabla} P_{f}$ where $\widetilde{K}_{f}$ is the fracture permeability and is determined from the geometry of $\Omega^{\prime}$. It turns out that $P_{p}$ and $P_{f}$ are such that $P_{p}=\mathrm{F}\left(P_{f}\right)$, where $\mathrm{F}$ is a non-linear time-dependent functional exhibiting memory effects.

The macroscopic behaviour is strongly influenced by the flow in the pores. It induces memory effects and strong non-linearities. This result highlights how the local effects may affect the macroscopic behaviour.

\section{Comparison With The Model Of Warren And Root}

To our knowledge, there is no rigorous phenomenological model for highly compressible fluid flow in fractured porous media. The existing models are derived for slightly compressible fluids. In these models, a pseudo steady state flow is described: it is assumed that the interporosity flow $q$, i.e. the flux of fluid from matrix to fractures, occurs in response to the fracture-pore difference in pressure:

$$
q=s K_{p}\left(P_{p}-P_{f}\right)
$$

where $s$ is a characteristic coefficient of the fractured rock proportional to the specific surface of the block. One of these classical models, namely, the model of Warren and Root can be compared to the homogenized model for the flow of a slightly compressible fluid.

From this comparison, it turns out that the model of Warren and Root cannot be identified to the long time approximation of the linearised homogenized model (Auriault \& Royer 1993), (Royer \& Auriault 1994), (Royer 1994). This shows that the model of Warren and Root fails to reproduce transient regimes and is ascribed to the pseudo steady state approximation, i.e. to the form of the interporosity flow term. However, the result of this comparison suggests a way to improve the interporosity term in the classical models. In effect, by using the following correction:

$$
q=s K_{p}\left(P_{p}-P_{f}-\theta \frac{\partial P_{f}}{\partial t}\right),
$$

where $\theta$ is a constant, it can be shown that the model of Warren and Root can be identified with the long time approximation of the homogenized model (Auriault \& Royer 1993), (Royer \& Auriault 1994), (Royer 1994).

\section{Conclusions}

Through classical phenomenological approaches, transport phenomena in dual porosity media are directly modelled at the macroscopic scale. Thus, the influence of local heterogeneities on the 
macroscopic behaviour cannot be perfectly disclosed. Furthermore, phenomena such as flow in the pores or storage capacity in the fractures are often simply discarded.

The homogenization method for periodic structures allows the derivation of the macroscopic behaviour from the complete microscopic description. Since there is no macroscopic prerequisite, the influence of the local effects is conveyed to the macroscopic level. Model (7) constitutes the first model of gas flow through a dual porosity medium that takes the strong compressibility of the fluid into account. Pseudo steady state phenomenological models are shown to be rough approximations for transient excitations in the context of slightly compressible fluid flow. Then, it is proved that adding a fracture pressure time derivative in the interporosity flow term overcomes, to some extent, the limitations of the pseudo steady state approximation.

\section{References}

Auriault, J.L. 1983. Effective macroscopic description for heat conduction in periodic composites. Int. J. Heat Mass Transfer, 26 (6):861-869.

Auriault, J.L. 1991. Heterogeneous medium - Is an equivalent macroscopic description possible? Int.J. Eng. Sci. 29(7): 785-795.

Auriault, J.L. \& Boutin C. 1992. Deformable porous media with double porosity - Quasi-statics, I: Coupling Effects. Transp. Por. Media, 7: 63-82.

Auriault, J.L. \& Boutin C. 1993. Deformable porous media with double porosity - Quasi-statics, II: Memory Effects. Transp. Por. Media, 10: 153-169.

Auriault, J.L. \& Royer, P. 1993. Double conductivity media: A comparison betweenphenomenological and homogenization approaches. Int. J. Heat Mass Transfer, 36 (10):2613-2621.

Auriault, J.L., Strzelecki, T., Bauer, J. \& He, S.1990. Porous deformable media saturated by a very compressible fluid: Quasi-statics. Eur. J. Mech. A/Solids, 9(4): 373-392.

Barenblatt, G.I. 1963. On certain boundary value problems for the equations of seepage of liquid in fissured rocks. $P P M$, 27(2): 348-350.

Barenblatt, G.I., Zheltov, I.P. \& Kochina, I.N. 1960.Basic concepts in the theory of seepage of homogeneous liquids in fissured rocks. $P . P M, 24(5): 852-864$.

Royer, P. 1994. Contribution de l'homogénéisation à l'étude de la filtration d'un gaz en milieu déformable à double porosité - Application à l'étude du système gaz-charbon. PhD thesis, Université Joseph Fourier, Grenoble, France.

Royer, P. \& Auriault, J.L. 1994. Transient quasi-static flow through a rigid porous medium with double porosity. Transp. Por. Media, 17: 33-57.

Royer, P., Auriault, J.L. \& Boutin, C. 1996. Macroscopic modeling of double-porosity reservoirs. J. Pet. Sci. Eng. 16: 187-202.Warren, J.R. \& Root , P.J. 1963. The behavior of naturally fractured reservoirs. Soc. Pet. Eng. J. Sept: $245-255$. 

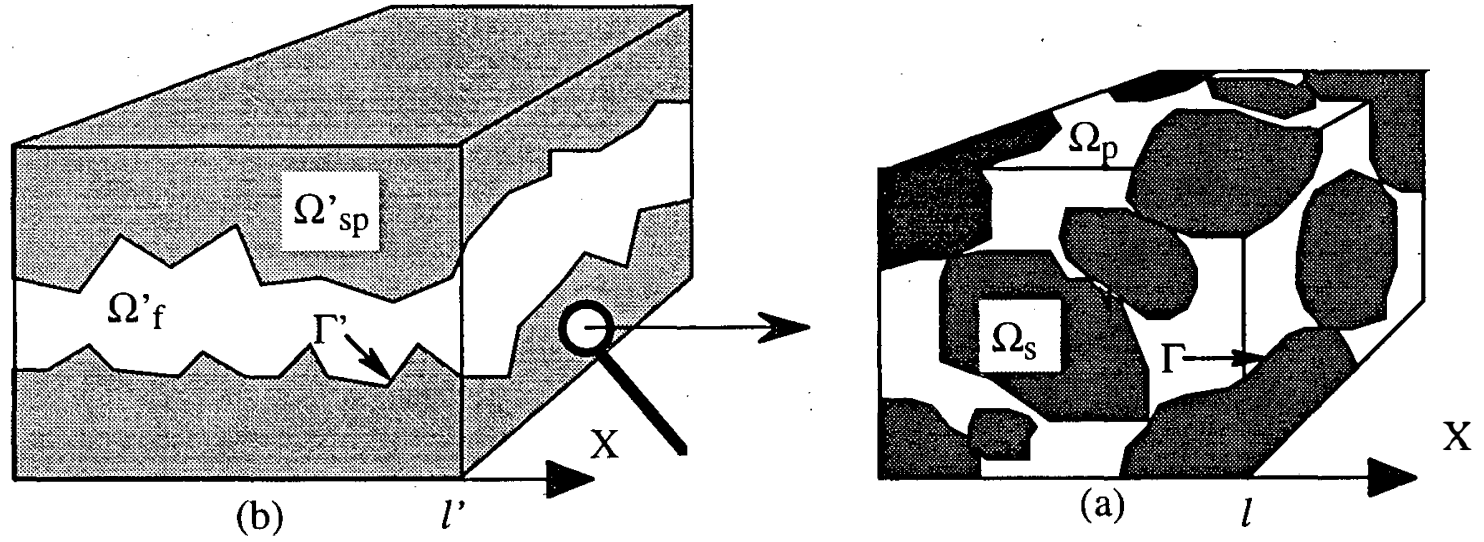

Figure 1: a) Fracture scale period; b) Pore scale period 